\title{
The effects of different compounds in some essential oils on in vitro gas production
}

\author{
U. Kilic ${ }^{1,4}$, M. Boga ${ }^{2}$, M. Gorgulu ${ }^{3}$ and Z. Şahan ${ }^{3}$ \\ ${ }^{1}$ University of Ondokuz Mayis, Faculty of Agriculture, Department of Animal Science \\ 55139 Samsun, Turkey \\ ${ }^{2}$ University of Nigde, Bor Vocational School \\ Bor, 51100 Nigde, Turkey \\ ${ }^{3}$ University of Cukurova, Faculty of Agriculture, Department of Animal Science \\ 01130 Adana, Turkey
}

(Received 21 December 2010; revised version 22 September 2011; accepted 6 December 2011)

\begin{abstract}
The aim of this study was to determine the effect of essential oils (EO) of oregano, ORE (Origanum vulgare); black seed, BSD (Nigella sativa); laurel, LAU (Laurus nobilis); cumin, CUM (Cumminum cyminum); garlic, GAR (Allium sativum); anise, ANI (Pimpinella anisum), and cinnamon, CIN (Cinnamomum verum) on in vitro gas production (IVGP) and IVGP kinetics of barley, wheat straw and soyabean meal. IVGP values were determined by using rumen liquor from three dry Holstein cows. The findings of this study indicate that the effects of EO, doses, and EO $\times$ dose interactions were significant. IVGP was decreased by ANI, GAR and ORE, and only CUM increased IVGP. These EO and their different doses or combinations in diets could be used to improve the performance of ruminants. Moreover, EO may act at different levels in energy and protein metabolic pathways, thus their careful selection and combination may be a useful tool to effectively manipulate rumen fermentation.
\end{abstract}

KEY WORDS: essential oils, in vitro gas production, barley, wheat straw, soyabean meal

\section{INTRODUCTION}

For decades, one of the goals of ruminant microbiologists and nutritionists has been to manipulate the ruminal microbial ecosystem to improve the efficiency of converting feeds to animal products edible by humans. The use of antibiotics

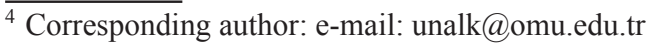


as feed additives, e.g., ionophore antibiotics, has proved to be a useful tool in reducing energy (methane) and nitrogen (ammonia) losses (McGuffey et al., 2001). The use of antibiotics as growth promoters in animal nutrition was banned after January 2006 in the European Union. For this reason in the last few years nutritonists have become increasingly more interested in bioactive plant factors that can modify rumen fermentation processes. The use of essential oils (plant extracts, phytofactors, volatile or etheral oils) appears to be one of the most natural alternatives to antibiotic use in animal nutrition. The possibility of using biologically active plant compounds for modulating changes in the rumen was first reported in 1911. In response to the requirements of animal production, the animal feed industry has marketed animal feed additives containing mixtures of secondary plant metabolites. Many researchers have demonstrated potentially favourable effects of mixtures of essential oils (Szumacher-Strabel and Cieślak, 2010).

Dong et al. (2010) reported that addition of some plant extracts to different diets reduced methane production. They reported that phytogenic products can be used as alternatives to monensin in altering in vitro rumen fermentation and reducing methane production in goats. The inclusion of oregano oil at different levels $(0,400,800$ and $1200 \mathrm{mg} / \mathrm{l})$ significantly decreased in vitro gas production, OMD and ME values. The inclusion of $1200 \mathrm{mg} / \mathrm{l} \mathrm{ORE} \mathrm{has} \mathrm{been} \mathrm{found} \mathrm{to} \mathrm{be} \mathrm{the}$ most effective dose, but a negative impact on the data was also seen. It can be said that low doses of essential oils should be used in ruminant nutrition but high doses of essential oils may decrease rumen function and feed efficiency (Canbolat et al., 2011). It is known that essential oils seem to have a detrimental effect on microbial fermentation when administered at high doses (Benchaar et al., 2007).

Many plant extracts have antimicrobial activities against a wide range of rumen microorganisms (Voda et al., 2003). Manipulation of the rumen microbial ecosystem for enhancing fibrous feed digestibility, reducing methane emission and nitrogen excretion by ruminants to improve their performance are some of the most important goals for animal nutritionists. Essential oils and their metabolites as natural feed additives are good candidates for achieving these objectives. Turkey is one of the largest aromatic plant and essential oil producers. The present study aimed to screen 7 plant extracts (essential oils) selected for rumen manipulations. Determination of the best doses of essential oils for optimization of rumen fermentation was the objective of this study.

\section{MATERIAL AND METHODS}

\section{Material}

This study was conducted from July 2008 to April 2009 at the University of Cukurova (Turkey). Seven essential oils (oregano, ORE (Origanum vulgare); 
black seed, BSD (Nigella sativa); laurel, LAU (Laurusnobilis); cumin, CUM (Cumminumcyminum); garlic, GAR (Allium sativum); anise, ANI (Pimpinella anisum) and cinnamon, CIN (Cinnamomum verum)) were used. Essential oils (plant extracts) were obtained from Hatay province (Turkey). Wheat straw, soyabean meal and barley were used as feedstuffs (substrates for incubation). Barley (highly degradable starch), soyabean meal (highly degradable protein) and wheat straw (fibre sources) were chosen to evaluate the effects of essential oils on starch, protein and fibre degradation in in vitro rumen fermentation. The samples were milled in a hammer mill through a $1 \mathrm{~mm}$ sieve for chemical analysis and in vitro gas production assays.

\section{Chemical analysis}

Dry matter (DM) was determined by drying samples at $105^{\circ} \mathrm{C}$ for $24 \mathrm{~h}$, ash content, by ashing in a muffle furnace at $550^{\circ} \mathrm{C}$ for $8 \mathrm{~h}$. Nitrogen $(\mathrm{N})$ content was estimated using the Kjeldahl method (AOAC, 1990). Neutral detergent fibre (NDF) and acid detergent fibre (ADF) determinations were based on the method of Van Soest et al. (1991) using an ANKOM fibre analyzer. Essential oils were bought from a commercial factory in Hatay Province and their composition (after distillation using a Neo-Clevenger apparatus) was determined by gas chromatography-mass spectrometry (Perkin Elmer Clarus model 500). All chemical analyses were carried out in triplicate.

In vitro gas production technique

Three dry Holstein cows with rumen cannulas (average liveweight of $650 \mathrm{~kg}$ ) were used in the in vitro gas production study. Approximately $200 \mathrm{mg}$ dry weight of samples (wheat straw, soyabean meal and barley) were weighed in triplicate into $100 \mathrm{ml}$ calibrated glass syringes following the procedures of Menke and Steingass (1988). The syringes were pre-warmed at $39^{\circ} \mathrm{C}$ before the injection of $30 \mathrm{ml}$ rumen fluid-buffer mixture (1:2) into each syringe and incubated in a water bath at $39^{\circ} \mathrm{C}$. McIntosh et al. (2003) reported that essential oil levels lower than 35,80 and $100 \mathrm{ppm}$ for various bacteria could not affect rumen fermentation. Cardozo et al. (2005) also reported that they studied five different doses $(0,0.3$, 3,30 and $300 \mathrm{ppm}$ ) of essential oils in their experiment. To determine the effects of essential oils on in vitro gas production and gas production kinetics, doses of 0 (control), 50, 100 and $150 \mathrm{ppm}$ were used. Gas volumes were recorded at 0 , $3,6,9,12,24,48,72$ and $96 \mathrm{~h}$ of incubation. Five repetitions of each sample were used in the in vitro gas production experiment. Rumen fluid was obtained from fistulated Holstein cows fed twice daily (08.30-16.30) with a diet containing 
maize silage $(60 \%)$ and concentrate $(40 \%)$. Cumulative gas production data were fitted to the model of Ørskov and McDonald (1979) by the NEWAY computer package programme:

$$
\mathrm{y}=\mathrm{a}+\mathrm{b}\left(1-\mathrm{exp}^{-\mathrm{ct}}\right)
$$

where: a - gas production from the immediately soluble fraction $(\mathrm{ml}), \mathrm{b}$ - gas production from the insoluble fraction $(\mathrm{ml}), \mathrm{a}+\mathrm{b}$ - potential gas production $(\mathrm{ml})$, $\mathrm{c}$ - gas production rate constant for the insoluble fraction $(\mathrm{ml} / \mathrm{h}), \mathrm{t}$ - incubation time (h), $\mathrm{y}$ - gas produced at time $\mathrm{t}$.

\section{Statistical analysis}

A completely randomised design was used to compare gas production and gas production kinetics using the general linear model (GLM) of the SPSS (SPSS version 10.0) programme package. The significance of differences between individual means was determined using Duncan's multiple comparation test:

$$
Y_{i j k}=\mu+\alpha_{i}+\beta_{j}+(\alpha \beta)_{i j}+e_{i j k}
$$

$Y_{i j k}$ - the observed value of $\mathrm{k}^{\text {th }}$ repetition of $\mathrm{j}^{\text {th }}$ dose of $\mathrm{i}^{\text {th }}$ plant extract; $\mu$ the population mean; $\alpha_{i}$ - the effect of $\mathrm{i}^{\text {th }}$ - plant extract; $\beta_{i}$ - the effect of $\mathrm{j}^{\text {th }}$ dose; $(\alpha \beta)_{i j}$ - interaction of $\mathrm{i}^{\text {th }}$ plant extract and $\mathrm{j}^{\text {th }}$ dose and $e_{i j k}$ - error term.

\section{RESULTS}

The main compounds of the essential oils were determined to be, \%: carvacrol (0.03), octadecadienoic acid methyl ester (51.04), hexadecanoic acid methyl ester (16.17), oleic acid methyl ester (23.13) in Nigella sativa; $\gamma$-terpinene (21.20), thymol (0.53) and carvacrol (57.01) in oregano; $\alpha$-piene (10.03), $\beta$-myrcene (14.71), eugenol (0.02) and 1.8 cineol (41.52) in laurel; (69.57), acetaugenol (6.58) and cinnamyl acetate (3.83) in cinnamon; linoleic acid (34.75), diallyldisulphide (25.00), dially tetrasulphide (1.69), diallytrisulphide (19.48) and allylmethyltrisulphide (5.24) in garlic; elaidic acid methyl ester (18.08), cuminyl aldehyde (13.13), safrana (3.36) and hexadecanoic acid methyl ester (15.49) in cumin; and isoanethol (2.49), limoene (1.14), cuparene (3.37) and anethol (79.56) in anise.

The chemical composition of barley, soyabean meal, and wheat straw and of feedstuffs used for cows, from which rumen fluid was obtained, is presented in Table 1. 
Table 1. Chemical compositions of the feedstuffs and forage and concentrate fed to animals, $\mathrm{g} / \mathrm{kg}$ DM

\begin{tabular}{lcccccccr}
\hline \multirow{2}{*}{ Feeds } & $\mathrm{DM}$ & $\mathrm{CP}$ & $\mathrm{EE}$ & $\mathrm{CF}$ & Ash & NFE & NDF & ADF \\
\cline { 6 - 10 } & $\mathrm{g} / \mathrm{kg}$ & \multicolumn{7}{c}{$\mathrm{g} / \mathrm{kg} \mathrm{DM}$} \\
Forage (maize silage) & 318.3 & 105.7 & 35.1 & 236.1 & 88.8 & 534.3 & 453.6 & 296.1 \\
Concentrates & 907.9 & 281.4 & 44.3 & 96.2 & 60.7 & 517.4 & 266.9 & 93.4 \\
Wheat straw & 92.93 & 40.28 & 12.85 & 457.60 & 69.75 & 419.5 & 814.9 & 570.1 \\
Soyabean meal & 92.08 & 448.40 & 19.98 & 60.59 & 79.95 & 391.1 & 125.2 & 113.3 \\
Barley & 90.30 & 131.68 & 18.36 & 72.90 & 40.57 & 736.5 & 222.5 & 97.9 \\
\hline
\end{tabular}

DM - dry matter, CP - crude protein, EE - ether extract, NFE - nitrogen free ectractives, NDF neutral detergent fibre, $\mathrm{ADF}$ - acid detergent fibre

The effects of different doses of essential oils on in vitro gas production of different feed ingredients are presented in Table 2. The findings of the present study indicate that essential oils, doses, and essential oil $\mathrm{x}$ dose interaction had significant effects $(\mathrm{P}<0.01)$ on gas production. Each essential oil, each incubation time and each feedstuff gave different results depending on the dose. The addition of CUM resulted in the highest in vitro gas production values in barley, soyabean meal and wheat straw, whereas the addition of ORE-150 gave the lowest values. BDS and LAU did not affect the in vitro gas production pattern of any of the three feeds $(\mathrm{P}>0.05)$.

The values obtained with barley using GAR-150, ORE-150 and ANI-100 were significantly lower than control values. On the other hand, those from CUM-100 and CUM-150 were higher than controls $(\mathrm{P}<0.05)$. The effects of BSD, LAU, CIN, CUM and ANI added to barley did not differ $(\mathrm{P}<0.05)$, however. Adding GAR150 and GAR-50 resulted in lower gas production at 12 and $24 \mathrm{~h}$ of incubation $(\mathrm{P}<0.05)$, but the difference disappeared at 48 and $96 \mathrm{~h}(\mathrm{P}>0.05)$.

In vitro gas production values of soyabean meal with the addition of ANI-50, ANI-100, ANI-150 and ORE-150 were lower than control, but were higher with CUM-50, CUM-100 and CUM-150 $(\mathrm{P}<0.05)$. Other essential oil treatments did not differ from the control. The effect of dose application of BSD, LAU, CIN and CUM to soyabean meal were not significant $(\mathrm{P}>0.05)$. Gas production at $12 \mathrm{~h}$ of the incubation was lower with the addition of ANI-150 and GAR-150 $(\mathrm{P}<0.05)$, but did not differ at other incubation times.

In vitro gas production of wheat straw with ANI-50, ANI-100, ANI-150, GAR-150 and ORE-150 was lower than in the control group, but higher when CUM-50, CUM-100 and CUM-150 were added $(\mathrm{P}<0.05)$. Additions of BSD were not efective. Lower gas production was obtained with the addition of ORE-150 and GAR-150 than with other doses. Gas production was also lower with CIN150 at $12 \mathrm{~h}$ of incubation, with LAU-150 at 12 and $24 \mathrm{~h}$, and with ANI-150 at 24 and $96 \mathrm{~h}(\mathrm{P}<0.05)$.

The influence of different doses of essential oils on gas production parameters of feeds used in the present study is presented in Table 3. Potential gas production 


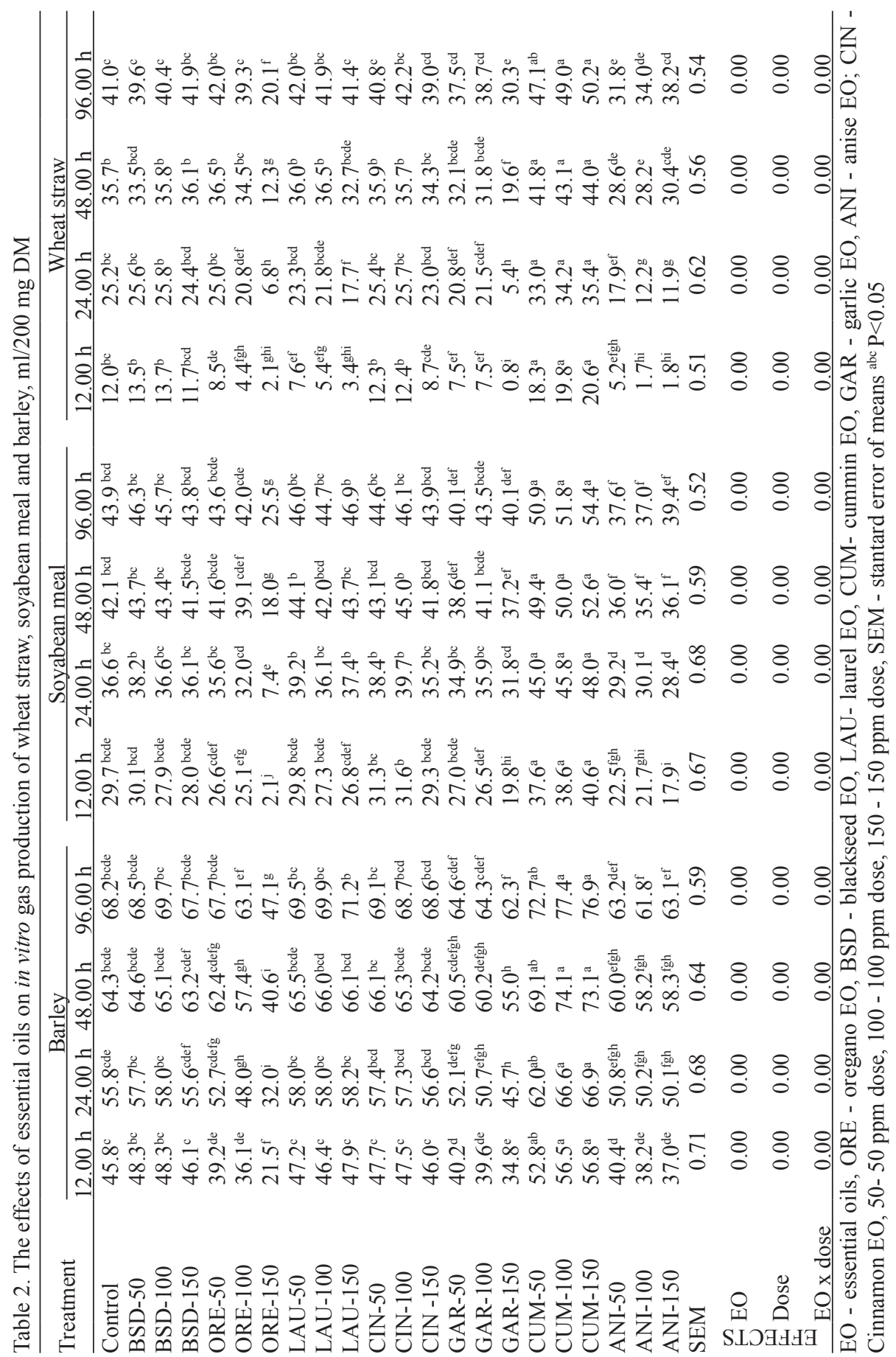




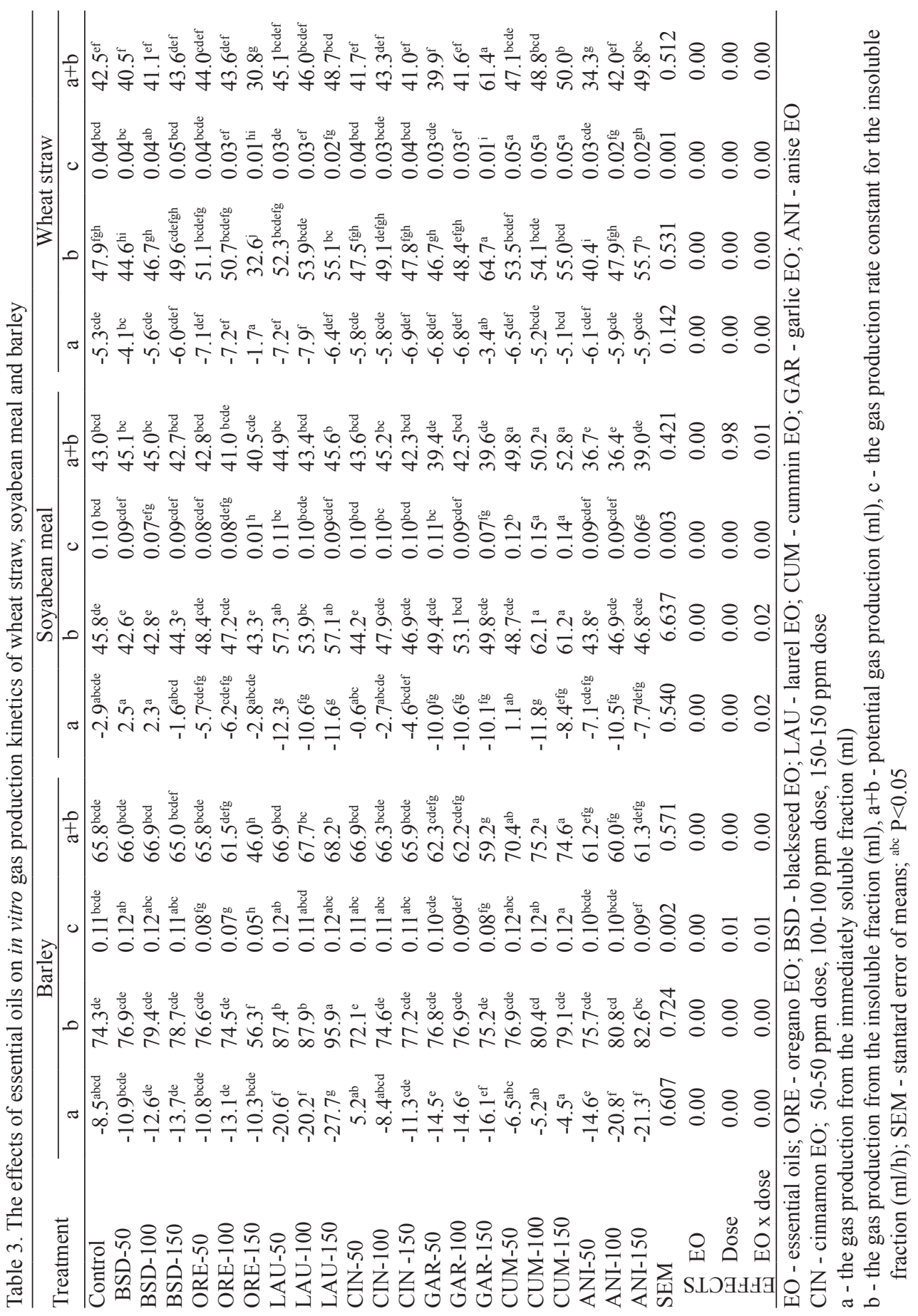


$(\mathrm{a}+\mathrm{b})$ of barley with CUM-100 and CUM-150 was higher than that of the control group, but lower with the addition of ORE-150 $(\mathrm{P}<0.05)$. The rate of gas production (c) in barley was higher with CUM-150, but was lower with ORE-50, ORE-100, ORE-150 and GAR150 than the control group $(\mathrm{P}<0.05)$. Doses of BSD, LAU, CIN and ANI had no effect on the values of $\mathrm{a}+\mathrm{b}$ or $\mathrm{c}(\mathrm{P}>0.05)$.

No differences were found among the doses of any of the essential oils in terms of the $\mathrm{a}+\mathrm{b}$ value in soyabean meal $(\mathrm{P}>0.05)$. Potential gas production, the $(\mathrm{a}+\mathrm{b})$ value, was higher with CUM-50, CUM-100 and CUM-150 and lower with ANI-50 and ANI-100 as compared with the control group. In soyabean meal, dose treatments with BSD, LAU and CIN did not differ in terms of c value. Higher ' $c$ ' values were obtained, however, when CUM-100 and CUM-150 were added; on the other hand, lower values were found with the addition of GAR-150, ANI-150, ORE-150 and BSD-150 ( $\mathrm{P}<0.05)$.

Treatment with BSD, LAU, CIN, CUM and ANI had significant effects in terms of $\mathrm{a}+\mathrm{b}$ value for wheat straw $(\mathrm{P}<0.05)$. LAU-150, GAR-150, CUM-100, CUM-150 and ANI150 produced higher $\mathrm{a}+\mathrm{b}$ values, whereas ANI-50 and ORE-150, lower values $(\mathrm{P}<0.05)$ in comparison with the control group. The 'c' value was not affected by treatments with BSD, CIN and CUM. As compared with the control group, addition of CUM-50, CUM-100 and CUM-150 resulted in higher values of $\mathrm{c}$, while that of ORE-100, ORE-150, LAU-100, LAU-150, GAR-100, GAR-150 and ANI-100, ANI-150 led to lower values $(\mathrm{P}<0.05)$.

\section{DISCUSSION}

Cardozo et al. (2004) reported that CIN, GAR, ORE and ANI changed rumen VFA proportions and that the results obtained by adding ANI and GAR suggested that deamination was inhibited. In this study, ORE-150 decreased in vitro gas production of all feeds. GAR-150 decreased in vitro gas production except for soyabean meal, in which it had no effect. These results are in agreement with the findings of Cardozo et al. (2004).

Decreased in vitro gas production by ORE may indicate more efficient utilization of energy due to the inhibited loss of energy as methane. An increasing trend for liveweight gain in lamb fattening by using oregano, oregano oil, and a commercial essential oil mix can be attributed to this effect (Akkan et al., 2006). In vitro gas production decreased for all feeds by increasing doses of essential oils in this study. Morover, ORE-150 showed the lowest in vitro gas production, which was similar to literature findings.

Benchaar et al. (2007) reported that in vitro gas production of carvacrol, thymol and eugenol decreased compared with controls. Those results are in agreement with the findings for ORE and CIN in this study. ORE and CIN possess more carvacrol and eugenol compounds respectively than other EOs.

UM increased, whereas ANI, GAR and ORE decreased in vitro gas production in barley. It is well known that there is a high correlation between in vitro gas production and both in vivo digestibility and/or microbial growth (Menke et al., 1979). These results showed that CUM could be used to improve digestion of slowly degradable starch, and 
ANI, GAR and ORE, to control degradation of highly degradable starch sources in the rumen to maintain ruminal $\mathrm{pH}$ within the physiological range. Cardozo et al. (2004) reported that GAR and CIN could inhibit deamination in the rumen. Similarly, lower gas production for soyabean meal with ANI and ORE and higher gas production with CUM may also suggest that protein degradation could be controlled by ANI and ORE. Furthermore, CUM might improve nitrogen utilization in the rumen if the diet was based on slowly degradable protein sources. In vitro gas production was decreased significantly by ANI, GAR and ORE, and only CUM increased gas production significantly. CUM may be used to improve cellulose digestion and could be considered a feed additive.

The decrease in total gas and methane production observed with the use of garlic oil confirms its ability to inhibit methanogenesis. Busquet et al. (2005) reported that in vitro gas production decreased as doses were increased. Patra et al. (2006) investigated the effects of water, methanol and ethanol extracts of garlic on rumen fermentation and methanogenesis. An aqueous garlic extract caused higher gas production and the ethanol and methanol extracts of garlic secondary metabolites appeared to have a potential to reduce rumen methanogenesis without adversely affecting rumen fermentation. The effects of Cordia verbenacea D.C. essential oil (EO) on ruminal fermentation were determined by using the in vitro gas production technique (Araujo et al., 2010). Inclusion of EO inhibited methanogenesis when hay was used as the substrate, but this effect was not seen with concentrate. These results showed that EO from Cordia verbenacea D.C. was able to modify in vitro ruminal fermentation when hay was the substrate. In this study, GAR-150 decreased in vitro gas production compared with controls, and ' $c$ ' values decreased as doses increased.

The effects of essential oils on rumen fermentation differ significantly. Carvacrol and thymol have strong antimicrobial activity against a wide range of gram-positive and -negative bacteria. Both are found in ORE (Sivropoulou et al.,1996). Castillejos et al. (2006) reported that low doses of thymol $(50 \mathrm{mg} / \mathrm{l})$ had no effects on in vitro rumen microbial fermentation. But at higher doses of thymol or ORE total VFA decreased (Castillejos et al., 2006) and decreased total gas production (Akkan et al., 2006; Benchaar et al., 2007; Kamalak et al., 2011). Furthermore, several in vitro studies have suggested that the effects of thymol are diet and pH dependent (Cardozo et al., 2005; Castillejos et al., 2006).

In the current experiment, the addition of ORE (thymol) decreased in vitro gas production. These findings are in agreement with the cited-above literature. On the other hand, the addition of ORE also decreased the gas production rate (h-1). This result is in agreement with Kamalak et al. (2011), but not with Benchaar et al. (2007).

Anethol is the main active component of ANI (79.56\%) and is responsible for its antimicrobial activity. In vitro studies with rumen fluid showed that anethol and ANI decreased total VFA production Calsamiglia et al. (2007) reported that ANI reduced the acetate-to-propionate ratio in the rumen, and may be beneficial in a beef production system. In this study, ANI-100 for barley, ANI-50 for soyabean and wheat straw decreased in vitro gas production compared with the control. These results are in agreement with the findings of Calsamiglia et al. (2007). 
Eugenol is one of the main active components of CIN (accounts for up to 69.57\%). The eugenol content in CIN in this study is in agreement with the findings of Davidson and Naidu (2000), who suggested that, when used at optimal doses, the efficiency of energy and protein utilization in the rumen was improved. Eugenol may improve VFA production and profile, and $\mathrm{N}$ utilization in the rumen of lactating animals (Castillejos et al., 2006). Different doses of CIN essential oils led to similar in vitro gas production levels in barley and soyabean meal. In vitro gas production levels of wheat straw were found to be lower for CIN-150 dose at $12 \mathrm{~h}$ incubation. CIN containing EUG might be used for improving rumen fermentation in forage-based diets. Therefore, this result is in agreement with the findings of Castillejos et al. (2006).

A commercial blend of essential oil compounds, the major components of which are carvacrol, thymol, eugenol, vanillin and limonene, can be used to manipulate rumen fermentation (McIntosh et al., 2003; Benchaar et al., 2007). In this study, CUM showed the highest in vitro gas production compared with controls for all of the feeds. ORE-150 showed the lowest in vitro gas production for all of the feeds. Moreover, there were important and varied interactions of feeds, doses and incubation times, which is in agreement with the findings of McIntosh et al. (2003). Benchaar et al. (2007) reported that the changes in rumen fermentation caused by essential oil compounds (thymol, carvacrol and eugenol) may not beneficial for dairy cattle. They suggest that the types and concentrations of EO and EO compounds must be carefully defined.

\section{CONCLUSIONS}

The results of this study suggest that the tested essential oils (EO) and their combinations influence rumen fermentation in a manner depending upon the EO and feeds used. In vitro results should be evaluated in in vivo studies.

\section{REFERENCES}

Akkan S., Soycan Önenc S., Bayram E., 2006. Possibilities of using some aromatic plants as feed additives in ruminant nutrition. Tubitak (VHAG-1984) and Ebiltem (2003/BIL/014) Project Final Report. İzmir (Turkey)

AOAC, 1990. Association of Official Analytical Chemists, Official Methods of Analysis. 15 Edition. Vol. 1. Washington, DC

Araujo R.C., Pires A.V., Abdalla A.L. et al., 2009. Effect of essential oil from Cordia verbenacea on the fermentation of a high-concentrate diet by using the in vitro gas production technique. In: Proceedings of FAO/IAEA International Symposium on Sustainable Improvement of Animal Production and Health, Vienna (Austria), pp. 170-171

Benchaar C., Chaves A.V., Fraser G.R., Wang Y., Beuchemin K.A., McAllister T.A., 2007. Effects of essential oils and their components on in vitro rumen microbial fermentation. Can. J. Anim. Sci. 87, 413-419

Busquet M., Calsamiglia S., Ferret A., Kamel C., 2005. Effects of cinnamaldehyde and garlic oil on rumen microbial fermentation in a dual flow continuous culture. J. Dairy Sci. 88, 2508-2516 
Calsamiglia S., Busquet M., Cardozo P.W., Castillejos L., Ferret A., Fandino I., 2007. The use of essential oils in ruminants as modifiers of rumen microbial fermentation. Pennsylvanic State Dairy Cattle Nutrition Workshop. Grantville, PA, pp. 87-100

Canbolat O., Kalkan H., Karaman S., Filya I., 2011. Effects of essential oils on digestibility, rumen fermentation and microbial protein production. Kafkas Univ. Vet. Fak. Derg. 17, 557-565

Cardozo P.W., Calsamiglia S., Ferret A., Kamel C., 2004. Effects of natural plants extracts on ruminal protein degradation and fermentation profiles in continuous culture. J. Anim. Sci. 82, 3230-3236

Cardozo P.W., Calsamiglia S., Ferret A., Kamel C., 2005. Screening for the effects of natural plants extracts at different $\mathrm{pH}$ on in vitro rumen microbial fermentation of a high-concentrate diet for beef cattle. J. Anim. Sci. 83, 2572-2579

Castillejos L., Calsamiglia S., Ferret A., 2006. Effect of essential oil active compounds on rumen microbial fermentation and nutrient flow in in vitro systems. J. Dairy Sci. 89, 2649-2658

Davidson P.M., Naidu A.S., 2000. Phyto-phenols. In: Natural Food Antimicrobial Systems. A.S. Naidu (Editor). CRC Press. Boca Raton, FL, pp. 265-293

Dong G.Z., Wang XJ., Liu ZB., Wang F., 2010. Effects of phytogenic products on in vitro rumen fermentation and methane emission in goats. J. Anim. Feed Sci. 19, 218-229

Kamalak A., Canbolat O., Ozkan C.O., Atalay A.I., 2011. Effect of thymol on in vitro gas production, digestibility and metabolizable energy content of alfalfa hay. Kafkas Univ. Vet. Fak. Derg. 17, 211-216

McGuffey R.K., Richardson L.F., Wilkinson J.I.D., 2001. Ionophores for dairy cattle: current status and future outlook. J. Dairy Sci. 84, Suppl. E, E194-E203

McIntosh F.M., Williams P., Losa R., Wallace R.J. Beever D.A., Newbold C.J., 2003. Effects of essential oil on ruminal microorganism and their protein metabolism. Appl. Environ. Microbiol. 69, 5011-5014

Menke K.H., Raab L., Salewski A., Steingass H., Fritz D., Schneider W., 1979. The estimation of the digestibility and metabolizable energy content of ruminant feedingstuffs from the gas production when they are incubated with rumen liquor in vitro. J. Agr. Sci. 93, 217-222

Menke K.H., Steingass H., 1988. Estimation of the energetic feed value obtained from chemical analysis and in vitro gas production using rumen fluid. Anim. Res. Develop. 28, 7-55

Ørskov E.R., McDonald I., 1979. The estimation of protein degradability in the rumen from incubation measurements weighted according to rate of passage. J. Agr. Sci. 92, 499-503

Patra A.K., Kamrai D.N., Agarwal N., 2006. Effect of spices on rumen fermentation, methanogenesis and protozoa counts in in vitro gas production test. Int. Congress Ser. 1293, pp. 176-179 (DOI:10.1016/j.ics.2006.01.025)

Sivropoulou A., Papanikolaou E., Nicolaou C., Kokkini S., Lanaras T., Arsenakis M., 1996. Antimicrobial and cytotoxicaktivities of origanum essential oils. J. Agr. Food Chem. 44, pp. $1202-1205$

Szumacher-Strabel M., Cieślak A., 2010. Potential of phytofactors to mitigate rumen ammonia and methane production. J. Anim. Feed Sci. 19, 319-337

Van Soest P.J., Robertson J.B., Levis B.A., 1991. Method for dietary fiber, neutral detergent fiber, and non-starch polysaccharides in relation to animal nutrition. J. Dairy Sci. 74, 3583-3597

Voda K., Boh B., Vrtacnik M., Pohleven F., 2003. Effect of the antifungal activity of oxygenated aromatic essential oil compounds on the white-rot tramatesversicolor and the brown-rot Coniophoraputana. Int. Biodeter. Biodegrad. 51, 51-59 